\title{
Psychosocial Adjustment Profiles of Gay and Lesbian Individuals Involved in Marital Relations: A Cluster-Based Analysis
}

\author{
Aline Nogueira de Lira ${ }^{1}$ \\ Normanda Araujo de Morais ${ }^{1}$
}

\begin{abstract}
Sexual minorities continue to face stressful environments arising from a heterosexist and homophobic system, endangering their health as well as their relational competence. This study characterizes psychosocial adjustment profiles from gay men and lesbians, verifying their differences according to socio-demographic data and protection factors. For such, 176 self-declared gay and lesbian participants, residents of Fortaleza, Aracaju and Uberaba, with stable marital relationships, responded to the following instruments: Internalized Homophobia Scales, Marital Satisfaction Scale, and the General Health Questionnaire. By using the cluster analytical method, four adaptive patterns were identified: resilient $(n=58)$; vulnerable $(n=41)$; competent $(n=43)$; and poorly adapted $(n=34)$. The identification of distinct profiles emphasized individual development paths, pointing out directions on how to promote resilience processes among sexual minorities that experienced such internal perception of stigma.
\end{abstract}

Keywords: resilience (psychology), risk factors, homosexuality, marital relations

\section{Perfis de Ajustamento Psicossocial de Gays e Lésbicas Envolvidos em Relacionamentos Conjugais: Uma Análise Baseada em Clusters}

\begin{abstract}
Resumo: Minorias sexuais continuam a enfrentar ambientes estressantes decorrentes do sistema heterossexista e homofóbico, colocando em risco a sua saúde, bem como a sua competência relacional. Esse estudo objetivou caracterizar perfis de ajustamento psicossocial de gays e lésbicas, verificando as suas diferenças de acordo com os dados sociodemográficos e os fatores de proteção. Para tal, 176 participantes autodeclarados gays e lésbicas, residentes de Fortaleza, Aracaju e Uberaba e que viviam relações conjugais estáveis, responderam os seguintes instrumentos: Escalas de Homofobia Internalizada, Escala de Satisfação Conjugal e o Questionário de Saúde Geral. Através do método analítico de cluster quatro padrões adaptativos foram identificados: resiliente $(n=58)$; vulnerável $(n=41)$; competente $(n=43)$; e mal adaptado $(n=34)$. A identificação de perfis distintos evidenciou trajetórias de desenvolvimento singulares, apontando direções sobre como promover processos de resiliência entre as minorias sexuais que vivenciaram a percepção interna do estigma.
\end{abstract}

Palavras-chave: resiliência (psicologia), fatores de risco, homossexualidade, relações conjugais

\section{Perfiles de Ajuste Psicosocial de Gays y Lesbianas en Relaciones Conyugales: Un Análisis con Base en Clusters}

\begin{abstract}
Resumen: Las minorías sexuales siguen enfrentando ambientes estresantes resultado del sistema heterosexista y homofóbico poniendo en riesgo su salud y su competencia en las relaciones. Este estudio tuvo como objetivo caracterizar los perfiles de ajuste psicosocial de gays y lesbianas, verificando sus diferencias según los datos sociodemográficos y los factores de protección. Para ello, 176 participantes homosexuales y lesbianas autodeclarados, residentes en Fortaleza, Aracaju y Uberaba y que se encontraban en estables relaciones conyugales respondieron los siguientes instrumentos: Escalas de Homofobia Internalizada, Escala de Satisfacción Conyugal y Cuestionario de Salud General. Utilizando el método analítico de cluster se identificaron cuatro estándares adaptativos: resiliente $(n=58)$; vulnerable $(n=41)$; competente $(n=43)$; y mal adaptado $(n=34)$. Los distintos perfiles identificados mostraron trayectorias de desarrollo singulares, destacando instrucciones sobre cómo promover procesos de resiliencia entre las minorías sexuales que experimentaron la percepción interna del estigma.
\end{abstract}

Palabras clave: resiliencia (psicología), factores de riesgo, homosexualidad, relaciones conyugales

${ }^{1}$ Universidade de Fortaleza, Fortaleza-CE, Brazil

Article derived from the doctoral thesis of the first author under the supervision of the second, defended in 2017, in the Graduate Program in Psychology at the University of Fortaleza. Support: This study had financial support from the National Council for Scientific and Technological Development - CNPQ (Process 471426/2014) and from the Edson Queiroz Foundation - FEQ (Project 1999/2016).

Correspondence address: Aline Nogueira de Lira. Universidade de Fortaleza. Avenida Washington Soares, 1321, Fortaleza-CE, Brazil. CEP 60.811-905. Email: aline.lira09@hotmail.com
Same-sex couples continue to face stressful and "socially toxic" environments (Garbarino, 1995), arising from the homophobic and heterosexual social system in which they are inserted, putting at risk their physical and mental health, as well as their relational competence (Lira \& Morais, 2018a). Although the visibility of relationships between gay and lesbian (LG) people is increasing, homophobic toxicity continues to be present in the lives of sexual minorities, whether by outsourced homophobia-e.g., 
hate crimes; violence; intimidation, or even internalized homophobia - when they internalize these social messages of exclusion and discrimination, resulting in negative feelings about oneself because of one's sexual orientation (Meyer, 2003).

Of the various processes related to sexual minority stress, internalized homophobia (IH) has been repeatedly mentioned in the literature as a chronic risk and potentially the most damaging to the physical and mental health of LGB people (Meyer, 2003). This is why self-directed negative feelings persist and may lead people to self-devalue even when they are not directly exposed to discrimination or prejudice, although $\mathrm{IH}$ is subjectively derived from heterosexist and homophobic social attitudes. Thus, IH has positively been associated with depression and anxiety, substance abuse, and risky sexual behavior, as well as interpersonal challenges such as reduction of social connectivity, omission of sexual orientation, and difficulty in conjugal intimacy (Rostosky \& Riggle, 2017a).

Even if we recognize the associations between internalized homophobia and the levels of psychosocial adjustment of LG people, recent studies, especially the ones using the theoretical model of resilience, have highlighted the coping and overcoming capacity of this population (Lira \& Morais, 2018a). Resilience has been conceptualized in the literature as the dynamic and interactive capacity of individuals, families and communities to successfully adjust to adversities that threaten their functioning or development (Wright \& Masten, 2015). This definition is intentionally broad and requires the recognition of at least two distinct dimensions: (1) the presence of situations and/or contexts of risk that threaten psychosocial adjustment; (2) the ability to "adjust successfully".

Psychosocial adjustment tells about the current state of development of each individual, which may be positive or negative (Infante, 2005). This successful adjustment has been evaluated mainly from the absence of psychopathology, fulfillment of socially expected developmental tasks, subjective well-being and relational competence (Wright \& Masten, 2015). In studies with the LG population, the main indicators of psychosocial adjustment are related to more individual aspects, such as psychiatric disorders (Lira \& Morais, 2018a). However, the analysis of the adaptive criteria of same-sex couples requires the observation of more relational aspects, which makes possible to evaluate the current state of development between the spouses. Being marital satisfaction "the result of a dynamic and interactive process of the couple that results in the evaluation that each spouse has on the level of quality that they experience in their marriage" (Mosmann, Wagner, \& Féres-Carneiro, 2006, p. 322), this variable may be an important criterion of psychosocial adjustment, signaling the efforts of couples to maintain or restore their relationship.
The third component of implied resilience that crosses this concept is the presence of protective factors, i.e. strategies and resources (personal and/or contextual) that can minimize the effect of risk and increase the probability of psychosocial adjustment (Vanderbilt-Adriance \& Shaw, 2008). Guided by the Broaden-and-build Theory (Fredrickson, 2004), a set of positive emotions (e.g., joy, contentment, amusement) enlarges the repertoire of thought and action, which stimulates the construction of new personal resources (whether physical, psychological, or social). These resources, in turn, act as reserves that facilitate the processes of resilience. On the other hand, negative emotions restrain the mental and action processes, limiting creativity, flexibility, and personal growth. Thus, positive affection can be a powerful protective factor to help people and same-sex couples to positively face adverse or crisis situations.

Regarding external protection factors, social support networks have played an important role in both mental health and marital satisfaction of same-sex couples. Many same-sex couples, inserted in a context of family and social rejection, go in search of other social support networks, such as friends and the LGBT community. The expansion of the social support network can counteract the negative effects of minority stress and allow better health and well-being outcomes for LGB people and couples (Lira \& Morais, 2018a).

On the methodological operationalization of resilience, in general, classic studies of resilience have favored the use of person-centered models assuming the individual, not the variables, as the focus of their analyses (Werner \& Smith, 1992). These analyses can be qualitative, such as case studies, or quantitative, such as cluster analyses. In quantitative investigations, variables-which have no meaning in themselves-are used only to construct patterns that classify participants by their individual scores. In this perspective, such studies have identified different adaptive profiles (high and low adaptive functioning) of individuals involved in multiple risks or threatening environments (high and low risk), to explain the differences in these groups (Masten, 2015; Wright \& Masten, 2015). From these classifications, the literature has highlighted four main adaptive profiles: (1) Poorly adapted: people with low-risk exposure but with low psychosocial adjustment; (2) Competent: individuals inserted in low-risk contexts but with high levels of adjustment; (3) Resilient: people involved in situations of significant adversity and with high levels of adjustment; and (4) Vulnerable: individuals who are at high risk and who have low indicators of psychosocial adjustment.

However, regarding studies with LG people, specifically, they have used, above all, the analytical approach centered on variables, that is, they seek to measure variables to explore links between risk, protection, and adaptive patterns through multivariate statistical analyses, without characterizing the individuality of the 
sample (Masten, 2015). In the systematic review of the literature between resilience and LG people performed by Lira and Morais (2018b), out of the 31 articles found in the electronic databases PsycINFO and PubMed up to 2015, only two studies used a quantitative person-centered approach (Bonanno, Moskowitz, Papa, \& Folkman, 2005; Livingston et al., 2015). One of these studies, for example, was conducted by Livingston et al., by grouping of clusters, in which they classified distinct personality profiles among young LGB adults: adaptive (lower neuroticism and higher extroversion, kindness, awareness, and openness); and at risk (higher neuroticism and kindness, conscientiousness, and openness and lower extroversion).

From the foregoing, we can see that, although resilience studies focusing on the LGBT person and population are emerging and beginning to offer clues about the differences between psychosocial adjustment patterns, very little is known about the potentially resilient profiles of gays and lesbians exposed to a homophobic context. To expand this field of research, therefore, the present study, based on the person-centered approach, sought to meet the following objectives: (1) to identify different profiles of psychosocial adjustment of gays and lesbians involved in a marital relationship; (2) to characterize and examine the differences between adjustment groups according to sociodemographic data; and (3) to compare the adaptive profiles of LG people, according to the protective factors. For the operationalization of the objectives, internalized homophobia was used as the main risk indicator. As adjustment indicators, marital satisfaction (relational adjustment) and general health (psychological adjustment) were included. Finally, as protective factors, satisfaction with social support (contextual resource) and positive/ negative affections (personal resources) were used.

The literature on resilience and LG people is still incipient. Thus, the findings of this study are expected to generate important implications for the implementation of social policies and effective interventions in the lives of sexual minorities. By classifying and comparing the different groups of people exposed to risks, both positively and negatively, one can shed light on the critical points that protect this population against adversity.

\section{Method}

\section{Participants}

This is a cross-sectional study of a larger one involving three Brazilian cities (Fortaleza, Aracaju, and Uberaba), and examining the resilience processes in gay and lesbian people engaged in a marital relationship $(N=303)$. Therefore, the instruments from only one of the conjugal dyad partners were analyzed, to not compromise the sample data. Thus, 176 people who declared themselves to be lesbians $(45.5 \%)$ and gays $(54.5 \%)$, with a mean age of 30.39 years $(S D=8.57)$, and who lived in the cities of Fortaleza-CE $(n=99,56.3 \%)$, Aracaju-SE $(n=59,33.5 \%)$, and Uberaba-MG ( $n=18,10.2 \%)$, were included in the research. Participants were engaged in stable relationships for 60.75 months $(S D=57.54)$ on average, of which $68.2 \%$ cohabited for an average of 51.16 months $(S D=49.17)$. In addition, only $12.1 \%(n=21)$ had children. Finally, of the total sample, $77.3 \%(n=192)$ worked and had an average individual income of about 3 minimum wages.

Recruitment of the initial sample followed some criteria for inclusion a priori: self-declaring as gay or lesbian; being in a homosexual relationship for at least one year and/or living with partner for at least 6 months and being 18 years old or older.

\section{Instruments}

Sociodemographic Questionnaire: Specially designed for this study by the authors of this article, this instrument consists of 24 questions that seek to characterize the participants with sociodemographic variables (age, sex, socioeconomic level, occupation, cohabitation, number of children, among others).

Internalized Homophobia Scale - HIS (Costa, Pereira, \& Leal, 2013): After the exploratory and factorial validation in the Brazilian population, the instrument, initially composed of 27 items and three factors, - public identification as homo(bi)sexual $[\alpha=0.789]$; internal perception of the stigma associated with homo(bi)sexuality $[\alpha=0.701]$; and perception of social oppression $[\alpha=0.693]$ (Costa et al., 2013) -, was constituted by 19 items, distributed in two factors: Internal Perception of Stigma $(\alpha=0.814)$ and Perception of Social Oppression $(\alpha=0.622)$. Items are measured on a 4-point Likert scale, from $0-$ totally disagree to 3 - totally agree. Examples of scale items are: "Obviously gay men make me feel uncomfortable," "I prefer having anonymous sexual partners," among others. For the analysis of the data, some items of the instrument were inverted so that the higher the levels of the scale, the greater the internalized homophobia. The adjustment and reliability indices of the present sample were as follows: $\chi^{2 /}$ $\mathrm{gl}=1.751 ; \mathrm{CFI}=0.886 ; \mathrm{RMSEA}=0.056 ; \mathrm{SRMR}=0.0637$; $\mathrm{F} 1-\alpha=0.803 ; \mathrm{F} 2-\alpha=0.610$.

General Health Questionnaire - GHQ-12 (Gouveia, Lima, Gouveia, Freires, \& Barbosa, 2012): GHQ-12 consists of 12 items that assess how much the participant has experienced symptoms related to psychological discomfort, and should be scored on a four-item scale $(\alpha=0.80$; Gouveia et al., 2012). In the case of negative items (e.g., "Have your concerns made you lose too much sleep?"), the response alternatives range from 1 absolutely not to 4 - much more than usual; and, in the case of positive items (e.g.; "Have you felt able to make decisions?"), responses ranged from 1 - more than usual to 4 - much less than usual. In this sense, the responses of the negative items were reversed, the lowest score 
indicating the best level of psychological well-being. In a confirmatory factor analysis, the bi-directional model was re-specified using a second-order factor, with two correlations between measurement errors. Such modifications enabled us to arrive at a one-way solution. The final adjustment of the model was considered poor in some indices, but acceptable $\left(\mathrm{x}^{2} / g l=2.354\right.$; CFI $=0.922$; RMSEA $=0.075 ;$ SRMR $=0.008 ; \lambda>0.450 ; \alpha=0.870$ ).

Golombok Rust Inventory of Marital State - GRIMS (Harth \& Falcke, 2017; Rust, Bennun, Crowe, \& Golombok, 1988): Consisting of 28 items, the instrument measures the quality of the conjugal relationship by a factorial dimension. After the confirmatory factorial analysis with the present sample, nine items of the instrument were eliminated and some of them were inverted so that the higher the scores obtained in the scale, the more satisfied people are in their marital relationship. Respondents were to score on a 4-point Likert scale (from 0 - Strongly disagree to 3 - Strongly agree). The questionnaire begins with the following reflection: thinking about your current relationship with your husband / wife / partner / boyfriend, answer the following questions: "My partner usually knows my needs and is sensitive to them," "I really appreciate my partner's sense of humor," among others. The adjustment and reliability indicators of the present sample were as follows: $\mathrm{x}^{2} / g l=2.121$; CFI $=$ $0.851 ;$ RMSEA $=0.068 ;$ SRMR $=0.0061 ; \alpha=0.86$.

Social Support Satisfaction Scale - SSSS (Marôco, Campos, Vinagre, \& Pais-Ribeiro, 2014): To evaluate the perception of social support in different contexts, the version of the instrument transculturally adapted between Brazil and Portugal was used, consisting of 12 items, distributed in four factors: satisfaction with friendships $(\alpha=$ $0.656)$; intimacy $(\alpha=0.673)$; satisfaction with family $(\alpha=0.649)$; and social activities $(\alpha=0.696)$. The items were in the affirmative form and measured on a 5-point Likert scale, from 0 - totally disagree to 4 - strongly agree. Some of the items on the scale are: "My friends do not look for me as many times as I would like," "I am satisfied with the number of friends I have," among others. The adjustment indicators of the present sample were as follows: $\mathrm{x}^{2} / \mathrm{gl}=1.545 ; \mathrm{CFI}=0.972$; $\mathrm{RMSEA}=0.047$; SRMR $=0.0479 ; \mathrm{F} 1-\alpha=0.695 ; \mathrm{F} 2-\alpha=0.725 ; \mathrm{F} 3-\alpha=$ $0.834 ; \mathrm{F} 4-\alpha=0.628$.

Positive and Negative Affect Scale (Damásio, Pacico, Polleto, \& Koller, 2013): This scale is derived from the Positive and Negative Affect Scale for Children PANAS-C34 (Giacomoni \& Hutz, 2006), consisting of 34 items and a bifactorial structure (Positive Affect $[\mathrm{PA}]-\alpha=0.84$; Negative Affect [NA] $-\alpha=0.88)$. The reduced version of the scale was used (Damásio et al., 2013), containing a two-factor structure with four items per factor, to measure positive and negative effects $(\alpha$ $\mathrm{PA}=0.77 ; \alpha \mathrm{NA}=0.76$ ). These are: fun, content, lively, harassed, humiliated, hurt, angry, and cheerful. Each adjective is evaluated by the participants on a five-point
Likert scale (from 0 - none to 4 - very much). The instrument had adequate psychometric characteristics for this sample: $\mathrm{x}^{2} / \mathrm{gl}=2.354$; CFI $=0.966$; RMSEA $=0.075$; $\mathrm{SRMR}=0.0563 ; \alpha \mathrm{PA}=0.842 ; \alpha \mathrm{NA}=0.661$ ).

\section{Procedure}

Data collection. The participants were recruited and invited to collaborate with the research by the dissemination in social networks and by the researchers' informal network in the three cities. When contacting participants, the snowball method was used, to identify other potential collaborators. The questionnaires were applied individually, and the participants took an average of 30 minutes to answer them. The collection took place from March 2015 to February 2016.

Data analysis. Cluster analysis was used to group participants into different profiles that may be more or less indicative of the adaptive process among LG people. Cluster analysis is an exploratory multivariate analysis technique that makes it possible to group subjects or variables into homogeneous groups, regarding certain common characteristics (Marôco, 2011).

For the grouping, the first step was to select the characteristics that guide this classification. Based on the person-centered theoretical model of resilience, the existence of four groups duly qualified by the criteria of levels of exposure to the risk and also of levels of positive adaptation is highlighted (Masten, 2015; Wright \& Masten, 2015), and they are: (1) Poorly adapted (low risk and low adaptation); (2) Competent (low risk and high adaptation); (3) Resilient (high risk and high adaptation); and (4) Vulnerable (high risk and low adaptation). For the mapping of adaptive patterns, the factors "internal perception of stigma" was considered an indicator of risk and "general health" and "marital satisfaction," indicators of psychosocial adjustment in same-sex couples. It should be noted, however, that the subscale "perception of social oppression" was suppressed from the analyses since it could not differentiate the clusters.

With the analytical procedure of the clusters, Ward's hierarchical method (with squared Euclidean distance criteria) was initially used to establish adequate initial values for the classification of k-means. From a range of 2 to 6 , the chosen solution followed the criteria of smaller number of groups, associated with the greater increase of explained variance (measured by changes in $\mathrm{R}^{2}$ ). Finally, by the nonhierarchical method, k-means clustering was used to compare groups with the same variance (Marôco, 2011).

Analysis of variance $\left(\eta^{2} p\right)$ made it possible to explore the means between the risk, protection, psychosocial adjustment variables and the different adjustment patterns, indicating the effect dimension. To explore the possible associations between the different adjustment groups and sociodemographic characteristics, chi-square statistic was used, with 
Monte Carlo simulation correction (Marôco, 2011). To measure the effect size, Cramer's V $(\varphi c)$ was used. Finally, we compared the means of the clusters with protection mechanisms (Social Support and its subscales, Negative Affect and Positive Affect) by ANOVA.

\section{Ethical Considerations}

The study was approved by the Ethics Committee of the University where the authors research (Opinion 715.705) and the Committees of partners Universities. The research meets the bioethical recommendations for research involving human beings, according to the National Health Council Resolution 466/2012 (CNS). All participants were informed about the objectives and procedures of the study and signed the Informed Consent Form - TCLE.

\section{Results}

From the hierarchical analysis of clusters, the solution with four clusters proved to be more appropriate to group the cases, with $57.40 \%$ of the explained variance. These clusters are statistically different from each other, both concerning the risk and the indicators of psychosocial adjustment. Table 1 presents the four profiles (Poorly adapted, Competent, Resilient, and Vulnerable) that emerged, as well as the ANOVA results for the risk and adjustment indicators of the four clusters.

Table 1

Risk measures and indicators of cluster adaptation

\begin{tabular}{|c|c|c|c|c|c|c|}
\hline & & $\begin{array}{c}\text { Resilient } \\
(n=58)\end{array}$ & $\begin{array}{l}\text { Vulnerable } \\
\quad(n=41)\end{array}$ & $\begin{array}{l}\text { Competent } \\
(n=43)\end{array}$ & $\begin{array}{l}\text { Poorly adapted } \\
\quad(n=34)\end{array}$ & $F(3,172)$ \\
\hline Internalized Homophobia (0-3) & $M(S D)$ & $0.93(0.27)^{\mathrm{B}}$ & $1.39(0.34)^{\mathrm{A}}$ & $0.37(0.24)^{\mathrm{D}}$ & $0.57(0.25)^{\mathrm{C}}$ & $\begin{array}{l}107.695^{* * *} \\
\eta_{p}^{2}=0.410\end{array}$ \\
\hline Marital satisfaction $(0-3)$ & $M(S D)$ & $2.13(0.20)^{\mathrm{C}}$ & $1.73(0.28)^{\mathrm{D}}$ & $2.50(0.18)^{\mathrm{A}}$ & $2.28(0.27)^{\mathrm{B}}$ & $\begin{array}{c}82.856^{* * *} \\
\eta_{p}^{2}=0.316\end{array}$ \\
\hline General health (1-4) & $M(S D)$ & $1.41(0.21)^{\mathrm{B}, \mathrm{C}}$ & $1.96(0.48)^{\mathrm{D}}$ & $1.38(0.27)^{\mathrm{B}}$ & $2.33(0.31)^{\mathrm{A}}$ & $\begin{array}{l}84.534^{* * *} \\
\eta_{p=}^{2} 0.393\end{array}$ \\
\hline
\end{tabular}

Note. Z-score based variable means; Different letters represent intercluster differences based on ANOVA $=p<0,001$;

*** $p<0,001$; The letters are ordered to show the increase/decrease of these values; High general health means indicate high psychological discomfort. In turn, the lower the mean overall health, the lower the psychological discomfort.

\section{Characterization of adaptive profiles}

Groups 1 and 2 were categorized as Resilient ( $n=58$; $33.0 \%)$ and Vulnerable $(n=41 ; 23.3 \%)$, respectively. Despite the Resilient cluster pointing out that its participants experienced high-risk situations, the results show that the LG people of this group are positively adjusted both psychologically and relationally: they presented a low average of psychological discomfort (that is, high general health) and a relatively high level of marital satisfaction (above the midpoint of the scale). In contrast, cluster 2 leaves no doubt as to its classification as Vulnerable: it shared the highest level of risk, with the second highest value of psychological discomfort (low overall health) and the lowest level of marital satisfaction.

Profiles 3 and 4 were named Competent $(n=43$, $24.4 \%)$ and Poorly adapted $(n=34,19.3 \%)$, respectively. The Poorly adapted) group, associated with the lowest risk, presented the highest value of psychological discomfort (an indicator of psychological adjustment) and third lowest value of conjugal satisfaction (relational adjustment indicator). Profile 3, Competent, showed the lowest level of internal perception of stigma, associated with the lowest level of psychological discomfort and the highest of marital satisfaction, leaving no doubt that it would be categorized as the Competent group.

\section{Adaptive profiles and sociodemographic characteristics}

From the chi-square test, significant differences were observed with small to medium effect size within the groups regarding the following aspects: sex of participants $\left[\chi^{2}(3)=9.216, p<0.05, \varphi c=0.229\right]$; schooling $\left[\chi^{2}(9)=\right.$ $15.576, p<0.05, \varphi c=0.182]$; work $\left[\chi^{2}(9)=15.943\right.$, $p<0.005, \varphi \mathrm{c}=0.301]$; religion $\left[\chi^{2}(3)=13.274, p<0.005\right.$, $\varphi c=0.275]$, and relationship time $\left[\chi^{2}(6)=15.485\right.$, $p<0.05, \varphi c=0.297]$. Table 2 shows the percentages of sociodemographic characteristics of the participants in the four clusters.

Based on the results of the chi-square test, the Resilient profile was predominantly gay, with more than five years 
of relationship and no religion. The Vulnerable group, in turn, presented a high number of participants with full secondary education, a job, and a relationship between 1 and 5 years. In this profile, none of the participants has more than 10 years of marital relationship. The Competent group, on the other hand, is formed mainly by lesbians, with no religion and mostly with undergraduate and graduate education. The Poorly adapted profile is predominantly composed of participants who do not work and do not have a religion.

There were no significant differences in age $\left[\chi^{2}(9)=\right.$ $10.783, p=0.290, \varphi c=0.143]$, individual income $\left[\chi^{2}(9)=\right.$ 8.638, $p=0.477, \varphi \mathrm{c}=0.128]$; cohabitation $\left[\chi^{2}(3)=7.477\right.$, $p=0.056, \varphi c=0.210]$; cohabitation time $\left[\chi^{2}(6)=10.819\right.$, $p=0.089, \varphi c=0.175]$; and presence of children $\left[\chi^{2}(3)=\right.$ $5.817, p=0.111, \varphi c=0.183]$.

Table 2

Percentages of sociodemographic characteristics in different adjustment profiles

\begin{tabular}{|c|c|c|c|c|c|}
\hline & $\begin{array}{c}\text { Resilient } \\
(n=58) \\
\%\end{array}$ & $\begin{array}{c}\text { Vulnerable } \\
(n=41) \\
\%\end{array}$ & $\begin{array}{c}\text { Competent } \\
(n=43) \\
\%\end{array}$ & $\begin{array}{l}\text { Poorly adapted } \\
\qquad \begin{array}{c}(n=34) \\
\%\end{array}\end{array}$ & $\begin{array}{c}\% \\
\text { of cases }\end{array}$ \\
\hline \multicolumn{6}{|l|}{ Sexual Orientation } \\
\hline Gay & $41.7^{1}$ & 24.0 & 19.8 & 14.6 & 54.5 \\
\hline Lesbian & ${\underline{22.5^{0}}}^{-}$ & 22.5 & $30.0^{1}$ & 25.0 & 45.5 \\
\hline \multicolumn{6}{|l|}{ Education } \\
\hline Lower than high school & 21.4 & 35.7 & 21.4 & 21.4 & 8.00 \\
\hline High school & 38.4 & $42.3^{1}$ & $\underline{3.8}^{0}$ & 15.4 & 14.80 \\
\hline Undergraduate & 36.8 & $\underline{13.7^{0}}$ & 28.4 & 21.1 & 54.00 \\
\hline Graduate & 24.4 & 29.3 & 29.3 & 17.1 & 23.20 \\
\hline \multicolumn{6}{|l|}{ Work } \\
\hline No & 30.0 & ${\underline{10.0^{0}}}^{\underline{9}}$ & 20.0 & $40.0^{1}$ & 22.70 \\
\hline Yes & 33.8 & $27.2^{1}$ & 25.7 & $\underline{13.2^{0}}$ & 77.30 \\
\hline \multicolumn{6}{|l|}{ Religion } \\
\hline No & $40.0^{1}$ & 16.7 & ${\underline{13.3^{0}}}^{-}$ & $30.0^{1}$ & 34.30 \\
\hline Yes & 28.7 & 27.0 & $30.4^{1}$ & ${\underline{13.9^{0}}}^{\underline{4}}$ & 65.70 \\
\hline \multicolumn{6}{|l|}{ Relationship time } \\
\hline 1-60 months & $26.1^{0}$ & $27.8^{1}$ & 25.2 & 20.9 & 65.30 \\
\hline $61-120$ months & 41.9 & 20.9 & 16.3 & 20.9 & 24.40 \\
\hline Above 120 months & $55.6^{1}$ & $\underline{0.0} \underline{0}$ & 38.9 & 5.6 & 10.20 \\
\hline
\end{tabular}

Notes. ${ }^{0-1}=$ Significant Associations (Chi-Square Statistics); ${ }^{0}=$ Lower frequency of observed $/$ expected cases; ${ }^{1}=$ Higher frequency of observed / expected cases.

\section{Adaptive profiles and protection indicators}

In the classification of the adaptive profiles, the risk and psychological and relational adaptation indicators were considered. But do the indicators of protection also differ among groups, corroborating the literature on resilience? To answer this question, we investigated whether the LG profiles were differently related to the following variables: perception of social support (friendship, intimacy, family, and social activities); positive affection; and negative affection. Table 3 shows the differences between the four clusters.
The analysis of variance (ANOVA) suggested significant differences between the adaptive profiles regarding protection features $(p<0,05)$. The Post Hoc LSD Test revealed that participants from the Resilient and Competent groups differed from the other groups and presented the highest means of protection, especially in support of friendship, intimacy, and social activities.

Vulnerable and Poorly adapted clusters, on the other hand, practically did not differed between themselves, obtaining the lowest averages in support of friendship, intimacy, family, and social activities and the highest means in negative affection. 
Table 3

Means between clusters and protection mechanisms

\begin{tabular}{|c|c|c|c|c|c|c|}
\hline & & $\begin{array}{l}\text { Resilient } \\
(n=58)\end{array}$ & $\begin{array}{l}\text { Vulnerable } \\
\quad(n=41)\end{array}$ & $\begin{array}{l}\text { Competent } \\
(n=43)\end{array}$ & $\begin{array}{l}\text { Poorly adapted } \\
\qquad(n=34)\end{array}$ & $\mathrm{F}(3,172)$ \\
\hline SS Friendship (0-4) & $M(S D)$ & $3.05(0.66) \mathrm{B}$ & $2.76(0.80) \mathrm{C}$ & 3.27 (0.79)A & $2.84(0.86) \mathrm{C}, \mathrm{D}$ & $3.620^{*}$ \\
\hline SS Intimacy (0-4) & $M(S D)$ & $3.06(0.75) \mathrm{B}$ & $2.54(0.80) \mathrm{C}$ & $3.24(0.89) \mathrm{A}$ & $2.79(0.97) C, D$ & $5.551 * *$ \\
\hline SS Family (0-4) & $M(S D)$ & $2.60(1.00) \mathrm{B}$ & $2.18(1.25) \mathrm{C}$ & $2.96(1.00) \mathrm{A}$ & $2.11(1.01) B, C, D$ & $5.694 * *$ \\
\hline SS Social Activities (0-4) & $M(S D)$ & $2.22(0.86) \mathrm{B}$ & $1.81(0.80) \mathrm{C}$ & $2.83(0.74) \mathrm{A}$ & $1.70(0.94) \mathrm{D}, \mathrm{C}$ & $15.314 * * *$ \\
\hline Positive Affection (0-4) & $M(S D)$ & $2.94(0.63) \mathrm{B}$ & $2.64(0.81) \mathrm{C}$ & $3.36(0.59) \mathrm{A}$ & $2.30(0.62) \mathrm{D}, \mathrm{C}$ & $17.825^{* * *}$ \\
\hline Negative affection (0-4) & $M(S D)$ & $0.64(0.40) \mathrm{A}$ & $1.23(0.71) \mathrm{B}$ & $0.70(0.58) \mathrm{A}$ & $1.38(0.76) \mathrm{B}, \mathrm{C}$ & $16.227 * * *$ \\
\hline
\end{tabular}

Note. Different letters represent intercluster differences based on ANOVA $=p<0,001 ;{ }^{*} p<0.05 ; * * p<0.01 ; * * * p<0.001$; The letters are ordered to show the increase / decrease of these values.

\section{Discussion}

This study aimed to classify and characterize different profiles of psychosocial adjustment in LGB individuals. The results pointed to four adjustment patterns, considering internal perception of stigma as indicator of risk, and psychological discomfort and marital satisfaction as indicators of psychosocial adjustment: Resilient, Vulnerable, Competent, and Poorly adapted. These results confirm the findings of previous resilience studies with a person-centered approach to identify the four adaptive profiles (Masten, 2015). The identification of distinct profiles, resulting from the interaction between risk situations and adaptive and maladaptive outcomes, showed unique developmental trajectories in a group of gays and lesbians. The groups presented in this study showed that not all LG people adjust in a homogeneous way, revealing high or low indexes of psychological and relational adjustment, according to the levels of exposure to adversity and to the interaction with other sociodemographic aspects and with systems of protection. For example, the more adaptive, competent, and resilient patterns, although differing in internal perception of stigma levels, have been shown to be more psychosocially adjusted than maladaptive and vulnerable groups. The Competent profile showed the lowest internal perception of stigma and the highest levels of general health and marital satisfaction. The Resilient profile, on the other hand, showed high levels of internal perception of stigma and low indicators of psychological discomfort. However, it presented the third lowest value of marital satisfaction among the groups (despite being above average), reporting a relative level of marital adjustment. On these differences, Luthar, Crossman, and Small (2015) report that, although both the Resilient and the Competent profiles present a positive adaptation, there are some differences between them. One of the differences consists in the understanding that, in the Resilient group, there is necessarily the presence of risk, and in the Competent profile there is not; moreover, the Competent profile indisputably reflects a positive adjustment. The Resilient pattern, however, can include both positive adjustment indices (health presence and absence of a disorder) and can simultaneously show negative adjustment indicators, given the exposure to adversities. That is, resilience is not a general approach, with uniformly positive adjustment in the various domains of life. In reality, people may present different spheres of adjustment, exhibiting strengths in some areas and deficits in others. Luthar et al. (2015) even point out that, by identifying this variety of domains in the adjustment indicators, researchers have adopted more specific terms to address resilience, such as: academic resilience, emotional resilience, and behavioral resilience. Based on these considerations, therefore, it is possible to state that, for the Resilient group in this study, the psychosocial adjustment was better regarding the lower index of psychological discomfort when compared to the satisfaction of the couple.

The Competent and Resilient groups obtained a larger number of participants to the detriment of the Vulnerable and Poorly adapted ones. Traditionally, researches using the four profiles report a lower frequency of participants in the Poorly adapted and Vulnerable groups. According to Wright and Masten (2015), these results possibly indicate a global perspective towards adaptive outcomes in human development and/or difficulty of access to highly vulnerable participants in scientific studies.

One result that deserves to be discussed is that the Poorly adapted profile showed that, even before the low risk of internal perception of stigma, LG participants presented high indicators of psychological discomfort. Interestingly, however, they presented relatively high marital satisfaction rates. That is, only the internal 
adjustment index (psychological discomfort) indicated poor adaptation, signaling that participants in this group are partially maladapted. A hypothesis for this finding is that, since conjugal satisfaction is a complex variable, resulting of a dynamic, relational, and contextual process (Mosmann et al., 2006), the presence of some other variables may have contributed to the positive assessment that spouses have of their marital relationship. In other words, the scientific literature on LGB individuals emphasizes that aspects such as the externalization of sexual orientation, intimacy, communication, cohesion, sexual functioning, and social support network can act as important protection factors positively associated with high levels of marital satisfaction (Knoble \& Linville, 2012). On the other hand, other adversities can lead same-sex couples to dual minority status, expanding their challenges, such as economic inequality, racism, ethnic issues, marital conflicts, lack of community and legal resources - or even specific adverse experiences of life, such as situations of illness, mourning, accidents, among others. Such contexts can also be risk indicators for these couples, affecting their adaptive function and the development of the family life cycle (Patterson, 2002). In addition, in the long term, the high levels of internal perception of stigma and psychological discomfort of partners may have implications in the couple's marital satisfaction (Rostosky \& Riggle, 2017b).

On associations between adjustment profiles and sociodemographic data, the groups with higher levels of risk (Resilient and Vulnerable) deserve some considerations. First, the prevalence of gays in the Resilient profile confirms the previous literature by showing that this population is part of the main risk group of sexual minorities, being the main victims of homophobic violence in Brazil (Ministério das Mulheres, da Igualdade Racial e dos Direitos Humanos, 2016). Another relevant question is about the effect of risk in the years of relationship between the spouses: in the Resilient profile, people with more than 10 years of relationship predominated, while the Vulnerable participants showed a lower relationship period (1 to 5 years). This observation suggests the understanding that, despite the presence of risk, it poses a threat to the quality of marital relationships (Rostosky \& Riggle, 2017a), and that it is a probabilistic term, not necessarily indicating the exact nature of the threat to an individual or couple (Wright \& Masten, 2015). Risks are multifaceted, and a more rigorous assessment of their effects needs to consider their cumulative effect, chronicity, and the ecological complexity that the person is involved in when facing the threat situation, as well as the relevance of the cultural and contextual factors that affect people facing risks (Wright \& Masten, 2015). In addition, even before adverse situations, same-sex couples may find in stress experiences an opportunity to strengthen their commitment to their spouses, in addition to bringing them closer and strengthening the marital bond (Rostosky \& Riggle, 2017b). Many couples deal effectively with minority stress and with efforts to conduct their strong relationships.
Also, on the different effects of risk on the adjustment indicators between the Resilient and Vulnerable groups, based on the theoretical model of resilience, the presence of protective factors may have minimized the impact of stress and collaborated to make people conjugally more satisfied. Moreover, the differences in the adjustment profile between the Resilient and Competent groups compared to the Poorly adapted and Vulnerable groups can also take place from the presence of both personal and contextual protective resources in the management of risk situations. Social support (especially in friendship, intimacy, and social activities) clearly served as a protective resource for LG people of the Resilient and Competent groups. Corroborating with other studies on resilience in LG people, the importance of social support to reduce retroactivity to internal perception of stigma is highlighted (Berg, Munthe-Kaas, \& Ross, 2016). In a social context of homophobia and oppression, social support can play at least two important roles: first, by making LG people feel connected, offering spaces of support and refuge; second, it can facilitate access to other important protection systems (social, institutional, educational, health), helping them to successfully manage their minority stress (Lira \& Morais, 2018a).

Regarding the perception of family support, although the people in the Resilient profile presented high levels of this type of support, their results did not differ from the Poorly adapted group. This indicates, therefore, that family support was not decisive for the (mal)adaptive success of sexual minorities. Often, one of the main areas of rejection that same-sex couples find, especially because of their sexual orientation, is within their families (Reczek, 2016). Thus, extended family, by friends, community connections, or even a fixed partner, effectively provide better adjustment results (Zimmerman, Darnell, Rhew, Lee, \& Kaysen, 2015).

When groups with low risk, such as Competent and Poorly adapted, were observed, we noticed that the first one is constituted mainly by lesbians with religion and the second, by gays and lesbians who do not work and with no religion. These characteristics show that having a religion seems to be an important protective resource in the quality of the psychosocial adjustment of gays and lesbians who are in marital relationships, especially when they have low levels of internal perception of stigma. Despite the conservative thinking of some religions, especially Christian ones, which reinforce prejudice against sexual diversity and are often positively associated with internalized homophobia (Cerqueira-Santos, Carvalho, Nunes, \& Silveira, 2017), having a religion, on the other hand, can favor the resilience processes, especially when gays and lesbians can transform the meaning of theology or even find an inclusive and affirming congregation.

Added to these characteristics, people in the Vulnerable group, as well as the Poorly adapted group, presented low levels of perception of social support (friendship, intimacy, family, and social activities) and positive affection, and high levels of negative affection. This suggests that the internal perception of stigma, associated 
with a lack of protection resources (internal and external), indicate the coexistence of adversities that seem to have more synergistic effects both individually (in mental health, for example) and conjugally, affecting the stability of the relationship between same-sex spouses. The long-term development implications for these profiles of LG people involve a decreasing confidence, given the variety of vulnerability estimates that coexist.

\section{Limitations and indications for future research}

Some limitations were imposed to this study and deserve to be highlighted to collaborate with future research. First, by choosing only internal perception of stigma as an indicator of risk, it was not possible to identify whether LG people were exposed to other adversities. Despite this limitation, it is understood that $\mathrm{IH}$ is a stressor of minorities related to socially constructed myths and stereotypes about homosexuality (Berg et al., 2016). Thus, along with it, other risks coexist, especially concerning the context of discrimination, legal non-protection, and absence of public policies for same-sex couples. This composite of adverse situations may together have more synergistic impacts on the adjustment indicators of this population (Luthar et al., 2015). New research should therefore include other risks and investigate their cumulative effect on sexual minorities. Additionally, adaptive indicators, such as externalization behaviors (suicide, drug use, risky sexual behavior), should also be explored, as well as normative development criteria (schooling, marrying, having children, working, etc.).

Regarding the composition of the sample, it consisted predominantly of middle-class, highly educated people recruited in urban areas and maintaining a stable marital relationship, which prevents us from making generalizations to gays and lesbians of other socioeconomic and educational levels, of rural origin and who do not have a stable relationship. Future studies should use other recruitment methods to target the population segments most exposed to risk and vulnerability.

This research, however, contributes to the advancement of the literature by classifying psychosocial adjustment profiles and observing the individual differences from the use of cluster analytical techniques. In addition, it offered clues on indicators of resilience in sexual minorities. Nevertheless, we recognize that it is only by studies with longitudinal designs that one can more accurately infer the effects of internalized homophobia on the adjustment profiles of gays and lesbians. Moreover, we understand that the analysis of the resilience processes experienced by this population requires studies with multiple methods and designs, which combine quantitative data collection strategies (such as the one presented in this study), but also focus on the description and understanding of how each person and couple of lesbian and gay people experience adversities and overcome them throughout their life.

In summary, the main findings of this research show four profiles of adjustment of gays and lesbians involved in marital relationships. The Resilient profile consisted mainly of gays; without religion; with more than 10 years of relationship; satisfied with the support of friendship, intimacy, and social activities; and with high averages of positive affection. The Vulnerable group consisted of people who work; have low levels of education; little relationship time; few means of protection (friendship, intimacy, social activities, family); and negative emotions/affections. The Competent profile, in turn, consisted mainly of lesbians who have a religion and a high level of schooling. Lastly, the Poorly adapted group consists of people who do not work; with no religion; with little social support; and high negative affections. The identification and characterization of adaptive patterns, based on a personcentered approach, revealed individual differences in personal and relational attributes regarding the psychosocial adjustment of LG people, thus showing that the LG population is not a homogeneous group with singular developmental trajectories. Examining these differences makes it possible to carry out intragroup analyses and guide qualitative research that can deepen the meanings that gays and lesbians give to their life trajectories. In addition, understanding these differences can be valuable in identifying and promoting the resilience of LG people and same-sex couples exposed to homophobic toxicity, showing the magnitude of the effects of the risks, but above all the strength of protection systems and sociodemographic characteristics that prevent and mitigate the effects of internalized homophobia on levels of psychosocial adjustment.

\section{References}

Berg, R. C., Munthe-Kaas, H. M., \& Ross, M. W. (2016). Internalized homonegativity: A systematic mapping review of empirical research. Journal of Homosexuality, 63(4), 541-558. doi:10.1080/00918369.2015.1083788

Bonanno, G. A., Moskowitz, J. T., Papa, A., \& Folkman, S. (2005). Resilience to loss in bereaved spouses, bereaved parents, and bereaved gay men. Journal of Personality and Social Psychology, 88(5), 827-843. doi:10.1037/00223514.88.5.827

Cerqueira-Santos, E., Carvalho, C. A. S. G., Nunes, L. M., \& Silveira, A. P. (2017). Homofobia internalizada e religiosidade entre casais homoafetivos [Internalized homophobia and religiosity among homosexual couples]. Temas em Psicologia, 25(2), 691-702. doi:10.9788/ TP2017.2-15

Costa, P. A., Pereira, H., \& Leal, I. (2013). Internalized homonegativity, disclosure, and acceptance of sexual orientation in a sample of Portuguese gay and bisexual men, and lesbian and bisexual women. Journal of Bisexuality, 13(2), 229-244. doi:10.1080/15299716.2013.782481

Damásio, B. F., Pacico, J. C., Poletto, M., \& Koller, S. H. (2013). Refinement and psychometric properties of the eight-item Brazilian Positive and Negative Affective Schedule for Children (PANAS-C8). Journal of Happiness Studies, 14(4), 1363-1378. doi:10.1007/s10902-012-9383-x 
Harth, J., \& Falcke, D. (2017). Manejo do Dinheiro e Qualidade Conjugal [Management of money and marital quality]. Interação em Psicologia, 21(1), 9-18. doi: 10.5380/psi.v21i1.32215

Fredrickson, B. L. (2004). The broaden-and-build theory of positive emotions. Philosophical Transactions of the Royal Society of London. Series B, Biological Sciences, 359(1449), 1367-1378. doi:10.1098/rstb.2004.1512

Garbarino, J. (1995). Raising children in a socially toxic environment. San Francisco, CA: Jossey-Bass.

Giacomoni, C. H., \& Hutz, C. S. (2006). Escala de afeto positivo e negativo para crianças: Estudos de construção e validação [Positive and negative affect schedule for children: Development and validation studies]. Psicologia Escolar e Educacional, 10(2), 235-245. Retrieved from http://pepsic.bvsalud.org/scielo.php?script=sci arttext\&pid=S1413-85572006000200007

Gouveia, V. V., Lima, T. J. S., Gouveia, R. S. V., Freires, L. A., \& Barbosa, L. H. G. M. (2012). Questionário de Saúde Geral (QSG-12): O efeito de itens negativos em sua estrutura fatorial [General Health Questionnaire (GHQ-12): The effect of negative itens in its factorial structure]. Cadernos de Saúde Pública, 28(2), 375-384. doi:10.1590/S0102-311X2012000200016

Infante, F. A. (2005). A resiliência como processo: Uma revisão de literatura recente [Resilience as a process: A recent literature review]. In A. Melillo \& E. N. S. Ojeda (Orgs.), Resiliência: Descobrindo as próprias fortalezas [Resilience: Discovering your own strongholds] (pp. 2338). Porto Alegre, RS: Artmed.

Knoble, N. B., \& Linville, D. (2012). Outness and relationship satisfaction in samegender couples. Journal of Marital and Family Therapy, 38(2), 330-339. doi:10.1111/j.17520606.2010.00206.x

Lira, A. N. \& Morais, N. A. (2018a). Resilience in Lesbian, Gay, and Bisexual (LGB) populations: An integrative literature review. Sexuality Research \& Social Policy, 15(3), 272-282. doi:10.1007/s13178-017-0285-x

Lira, A. N., \& Morais, N. A. (2018b). Methodological strategies for resilience research in Lesbians, Gays and Bisexuals (LGBs): Integrative review of the literature. Trends in Psychology, 26(3), 1447-1465. doi:10.9788/ TP2018.3-11En

Livingston, N. A., Heck, N. C., Flentje, A., Gleason, H., Oost, K. M., \& Cochran, B. N. (2015). Sexual minority stress and suicide risk: Identifying resilience through personality profile analysis. Psychology of Sexual Orientation and Gender Diversity, 2(3), 321-328. doi:10.1037/sgd0000116
Luthar, S. S., Crossman, E. J., \& Small, P. J. (2015). Resilience and adversity. In R. M. Lerner (Series Ed.) \& M. E. Lamb (Vol. Ed.), Handbook of child psychology and developmental science: Vol. 3. Socioemotional processes (7th ed., pp. 247-286). New York, NY: Wiley.

Marôco, J. (2018). Análise estatística com o SPSS Statistics [Statistical analysis with SPSS Statistics] (7th ed.). Pêro Pinheiro, Portugal: ReportNumber.

Marôco, J. P., Campos, J. A. D. B., Vinagre, M. G., \& PaisRibeiro, J. L. (2014). Adaptação transcultural BrasilPortugal da Escala de Satisfação com o Suporte Social para estudantes do ensino superior [Brazil-Portugal transcultural adaptation of the Social Support Satisfaction Scale for college students]. Psicologia: Reflexão e Crítica, 27(2), 247-256. doi:10.1590/1678-7153.201427205

Masten, A. S. (2015). Ordinary magic: Resilience in development. New York, NY: Guilford.

Meyer, I. H. (2003). Prejudice, social stress, and mental health in lesbian, gay, and bisexual populations: Conceptual issues and research evidence. Psychological Bulletin, 129(5), 674-697. doi:10.1037/0033-2909.129.5.674

Ministério das Mulheres, da Igualdade Racial e dos Direitos Humanos. Secretaria Especial de Direitos Humanos. (2016). Relatório de violência homofóbica no Brasil: Ano 2013 [Report of homophobic violence in Brazil: Year 2013]. Brasília, DF: Secretaria Especial de Direitos Humanos. Retrieved from http://www.direito.mppr.mp.br/arquivos/File/ RelatorioViolenciaHomofobicaBR2013.pdf

Mosmann, C., Wagner, A., \& Féres-Carneiro, T. (2006). Qualidade conjugal: Mapeando conceitos [Marital quality: Mapping out concepts]. Paidéia (Ribeirão Preto), 16(35), 315-325. doi:10.1590/S0103-863X2006000300003

Patterson, J. M. (2002). Integrating family resilience and family stress theory. Journal of Marriage and the Family, 64(2), 349-360. doi:10.1111/j.1741-3737.2002.00349.x

Reczek, C. (2016). Parental disapproval and gay and lesbian relationship quality. Journal of Family Issues, 37(15), 2189-2212. doi:10.1177/0192513X14566638

Rostosky, S. S., \& Riggle, E. D. B. (2017a). Same-sex couple relationship strengths: A review and synthesis of the empirical literature (2000-2016). Psychology of Sexual Orientation and Gender Diversity, 4(1), 1-13. doi:10.1037/sgd0000216

Rostosky, S. S., \& Riggle, E. D. B. (2017, January 9). SameSex Couple Relationship Strengths: A

Review and Synthesis of the Empirical Literature (2000 2016). Psychology of Sexual Orientation and Gender Diversity. Advance online publication. http://dx.doi.org/ $10.1037 /$ sgd0000216 
Rostosky, S. S., \& Riggle, E. D. B. (2017b). Same-sex relationships and minority stress. Current Opinion in Psychology, 13, 29-38. doi:10.1016/j.copsyc.2016.04.011

Rust, J., Bennun, I., Crowe, M., \& Golombok, S. (1988). The Golombok Rust Inventory of Marital State. Windsor, United Kingdom: NFER-NELSON.

Vanderbilt-Adriance, E., \& Shaw, D. S. (2008). Conceptualizing and re-evaluating resilience across levels of risk, time, and domains of competence. Clinical Child and Family Psychology Review, 11(1-2), 30-58. doi:10.1007/s10567-008-0031-2

Werner, E. E., \& Smith, R. S. (1992). Overcoming the odds: High risk children from birth to adulthood. Ithaca, NY: Cornell University Press.

Wright, M. O. D., \& Masten, A. S. (2015). Pathways to resilience in context. In L. C. Theron L. Liebenberg, \& M. Ungar (Eds.), Youth resilience and culture: Commonalities and complexities (pp. 3-22). Dordrecht, The Netherlands: Springer.

Zimmerman, L., Darnell, D. A., Rhew, I. C., Lee, C. M., \& Kaysen, D. (2015). Resilience in community: A social ecological development model for young adult sexual minority women. American Journal of Community Psychology, 55(1-2), 179-190. doi:10.1007/s10464-0159702-6

Aline Nogueira de Lira is a Professor at the Universidade de Fortaleza, Fortaleza-CE, Brazil.

Normanda Araujo de Morais is a Professor at the Programa de Pós-Graduação em Psicologia of the Universidade de Fortaleza, Fortaleza-CE, Brazil.

Authors' Contribution:

All authors made substantial contributions to the conception and design of this study, to data analysis and interpretation, and to the manuscript revision and approval of the final version. All the authors assume public responsibility for the content of the manuscript.

Received: Jan. 23, 2018

1st Revision: Apr. 22, 2018

Approved: May. 06, 2018

How to cite this article:

Lira, A. N., \& Morais, N. A. (2020). Psychosocial adjustment profiles of gay and lesbian individuals involved in marital relations: A cluster-based analysis. Paidéia (Ribeirão Preto), 30, e3013. doi:http://dx.doi.org/10.1590/1982-4327e3013 